\title{
SOCIAL CREATIVITY: A COMPARISON OF INDIVIDUAL VERSUS GROUP PERFORMANCE ON A CREATIVE TASK
}

\author{
*John Leddo, Bhadra Kadangal, Sadhana Mallemudi, Siddarth Mallemudi \\ MyEdMaster, LLC, 13750 Sunrise Valley Drive, Herndon, VA, United States of America \\ *Corresponding Author and director of research at MyEdmaster
}

DOI: 10.46609/IJSSER.2020.v05i03.009 URL: https://doi.org/10.46609/IJSSER.2020.v05i03.009

\begin{abstract}
Creativity is the ability to transcend ideas, rules, relationships, patterns to form meaningful ideas, forms, methods, interpretations, etc. Society often thinks of creative individuals as working in isolation, and much research has been conducted to identify personality and other traits that lead to though intelligence and creativity result in large part from interaction and collaboration with other individuals. Much human creativity is social, arising from activities that take place in a context in which interaction with other people and the artifacts that embody collective knowledge are essential contributors. The purpose of the present paper is to identify whether people work more creatively as individuals or in groups. 33 middle and high school students worked either individually or in groups of two to create ideas for television shows to be aired on a social media platform. Entries were judged on their creativity and a $\$ 100$ prize for most creative entry was offered to motivate the participants. Results showed that television show ideas created by pairs of students were judged as more creative than those created by individual students.
\end{abstract}

Keywords: Social Creativity, Performance, Society, Working together, MyEdMaster

\section{INTRODUCTION}

Creativity is a topic that has long fascinated people and has been the subject of considerable scientific research. Earlier research focused on identifying what creativity is and how it differs from ordinary problem solving. Initial definitions of creativity included high quality, original and elegant solutions to problems (Besemer and O'Quin, 1999; Christaans, 2002; Mumford and Gustafson, 1988). 


\section{International Journal of Social Science and Economic Research}

ISSN: $2455-8834$

Volume: 05, Issue: 03 "March 2020"

Subsequently, researchers turned their attention to both situational and personality conditions that gave rise to creativity. For example, Amabile and Pratt (2016) describe creativity as the result of task motivation, domain-relevant knowledge and creativity-relevant skills. On the personality side, researchers have found a link between creativity and personality traits such as self-confidence, enthusiasm, hard-working, tolerance for ambiguity, risk-taking, emotional, hostile and bitter (Feist, 1998; Martindale, 1989; Redmond et al., 1993).

In spite of the tremendous interest in individual creativity, there seems to be less focus on group creativity (James and Drown, 2012). Group or social creativity plays an increasingly larger role in our society. One of the most recent and pervasive forms of social creativity comes through crowdsourcing, where a problem is presented through a social media platform and solutions are gathered (Ryu, 2019). Typically, with crowdsourcing, a question is posed through social media and responses are sought. Crowdsourcing relies on the statistical concept that with thousands or even more minds working on a problem, a good solution is likely to be found. While it is possible that some of the solutions generated are actually the product of groups working together and submitting a single idea, the crowdsourcing paradigm does not have the means to determine when this occurs or even whether the resulting winning solution was the result of an individual or a team.

Other researchers have examined the creative results of people working together. Competing results have been found. In a classic framework, Irving Janis found that in groups of problem solvers, a phenomenon called "groupthink" may occur where members of the group suppress any solutions that do not conform with the group's consensus (Janis, 1991). Other researchers have argued that in group situations, individuals build upon each other's ideas, thus producing a more creative solution (Paulus \& Brown, 2007; Paulus et al., 2018).

While we do not expect one experiment to resolve the debate as to whether individuals are more creative than groups, the present study attempts to add some clarification to the issue by having people engage in a purely creative task when working either as an individual or in a group of two setting. In the present study, participants were asked to develop an original idea for a television show to be aired on a social media website. We hypothesize that people working in groups of two would come up with more creative ideas than those working individually.

\section{METHODS}

\section{Participants}

Participants were 33 middle and high school students recruited from local schools in Fairfax and Loudoun Counties in Virginia, USA. Of the 33 student, 22 were assigned to work in teams of 


\section{International Journal of Social Science and Economic Research}

ISSN: $2455-8834$

Volume: 05, Issue: 03 "March 2020"

two and 11 worked as individuals. Participants were told that they were entering a contest to create an idea for a TV show that could be made into a delivered over a web-based social media platform and for which the winning entry would receive $\$ 100$ and the student(s) would be credited as creator(s) of the show. This was done to motivate all students to take the assignment seriously and do their best.

\section{Materials and Procedure}

Participants were given an instruction sheet and submission form on the same sheet of paper. At the top of the sheet was the set of instructions that described the requirements of the task. The instructions stated that MyEdMaster had created a social media website and was looking for ideas for TV shows. Participants were asked to come up with an idea for a TV show that met the following constraints: the show must be filmable at a MyEdMaster center or nearby locations using MyEdMaster students as actors and must be family appropriate and free of violence or bad language. Participants were given one hour to create the show and were not allowed to use outside resources other than their partners in the team condition. They were told that all entries would be judged on the basis of creativity. To incentivize participants to try their best, they were told the winning entry would receive $\$ 100$ and the authors would be credited as creators of the show if it were made into a TV show.

After the instructions, the form contained sections for the participants to fill in to submit their ideas. These sections included: the title of the show: whether or not the show would be animated: the concept or plot of the show: the setting, plot and actors; an example of an episode and if there would be multiple episodes; what is unique about the show; and any other details the participants wanted to add.

When all the show ideas were collected, they were given to four judges to score. Only the TV show ideas were given to the judges; there was no indication of who the authors were or whether the authors worked individually or in pairs. The judges worked in pairs in order to create a consensus on the quality of the entries. The judges gave each story a score based on a rubric provided to them. The scoring system was based on four factors: originality/creativity, an interesting plot, a realistic story (for the show), and a topic that would increase popularity for the show. The grading system had a score range from 1-5 (1 being poor and 5 being exceptional) per factor for a maximum potential total of 20 points.

\section{RESULTS}

As discussed in the Materials and Procedure section, each TV show entry was scored on a 20point scale. Shows receiving higher scores were deemed to be more creative. Our hypothesis 
International Journal of Social Science and Economic Research

ISSN: $2455-8834$

Volume: 05, Issue: 03 "March 2020"

was that people working in groups would be more creative than those working individually. This was tested by comparing the mean creativity ratings of TV shows produced by groups to those produced by individuals. The mean rating for group-produced shows was 16.5 and that for individual-produced shows was 12.1. A t-test was performed on the data and was found to be statistically significant, $\mathrm{t}=2.77, \mathrm{df}=20, \mathrm{p}=.012$, confirming our hypothesis that individuals working in groups are more creative than those working alone.

\section{DISCUSSION}

The results of the experiment suggest that people working in groups are more creative than those who work individually as evidenced by the creativity scores of the TV show ideas they created. One potential explanation for this might be that given that groups have two people in them, there is a greater likelihood that at least one of them would be creative such that the group product is just a reflection of the creativity of the more creative individual providing the solution by himself or herself rather than a byproduct of creativity enhanced through group interaction. However, an examination of individual scores of both group and individual TV show entries suggests that this explanation is not true.

For group scores, the minimum score achieved was 16 out of 20, suggesting that all entries were of high quality. However, of the 11 individual entries, only 4 of them scored 16 or higher. This suggests that while there are creative individuals, there are not sufficient numbers of them to insure that every group has a creative individual. On the other hand, given that three of 11 individuals scored below 10, the implication is that when working in groups, even individuals of lower creativity can be elevated through collaboration with a partner, even if the partner also has lower creativity. This hypothesis should be tested experimentally by first evaluating individuals as to their creativity and then pairing low scoring individuals with other low scoring individuals to see if they become high scoring when working as a pair.

While the present results suggest that the presence of a group enhances creativity compared to individuals working alone, there is also a body of research that examines conditions under which groups of decision makers perform worse than individuals such as cases where groupthink is involved (cf. Janis, 1991). Of interest would be to conduct research to investigate whether elements of groupthink pervade the creative process as well as decision making processes. If so, this may suggest ways in which group creativity can also be impaired and necessitate ways to mitigate such impairments.

\section{CONCLUSION}


International Journal of Social Science and Economic Research

ISSN: $2455-8834$

Volume: 05, Issue: 03 "March 2020"

The results showed that groups are more creative than individuals most of the time. Most of the group TV shows scored higher than did the individual TV shows. The data do not apply to all cases as some particular individuals are more creative than group members, but this appears to be a general trend. While further research is needed to investigate optimum composition of creative groups and whether group settings can induce biases or other hindrances to peak group creativity, it appears that if organizations have creative tasks that need to be performed, as was the case with the social media platform, a better result will be obtained if that organization uses a group rather than an individual to perform the task.

\section{REFERENCES}

Amabile, T. M., \& Pratt, M. G. (2016). The dynamic componential model of creativity and innovation in organizations: Making progress, making meaning. Research in Organizational Behavior, 36, 157-183.

Besemer, S. P., \& O'Quin, K. (1999). Confirming the three-factor creative product analysis matrix model in an American sample. Creativity Research Journal, 12(4), 287-296.

Christiaans, H. H. (2002). Creativity as a design criterion. Communication Research Journal, $14(1), 41-54$.

Feist, G. J. (1998). A meta-analysis of personality in scientific and artistic creativity. Personality and social psychology review, 2(4), 290-309.

Janis, I. L. (1991). Groupthink. Markham, Ont.: Owen Stewart Performance Resources

James, K., \& Drown, D. (2012). Organizations and creativity: trends in research, status of education and practice, agenda for the future. In Handbook of organizational creativity (pp. 17-38). Academic Press.

Madrid, H. P., \& Patterson, M. G. (2018). Affect and Creativity. In Individual creativity in the workplace (pp. 245-265). Academic Press.

Martindale, C. (1989). Personality, situation, and creativity. In Handbook of creativity (pp. 211232). Springer, Boston, MA.

Mumford, M. D., \& Gustafson, S. B. (1988). Creativity syndrome: Integration, application, and innovation. Psychological bulletin, 103(1), 27. 
Paulus, P. B., \& Brown, V. R. (2007). Toward more creative and innovative group idea generation: A cognitive-social-motivational perspective of brainstorming. Social and Personality Psychology Compass, 1(1), 248-265.

Paulus, P. B., Baruah, J., \& Kenworthy, J. B. (2018). Enhancing collaborative ideation in organizations. Frontiers in psychology, 9.

Redmond, M. R., Mumford, M. D., \& Teach, R. (1993). Putting creativity to work: Effects of leader behavior on subordinate creativity. Organizational behavior and human decision processes, 55(1), 120-151.

Ryu, S. (2019). The Beauty of Crowdfunding. Oxfordshire, UK: Routledge Taylor and Francis Group. 